\title{
INFORMÁTICA NA EDUCACְÃO MATEMÁTICA E CIENTÍFICA DOS ANOS INICIAIS DE ESCOLARIDADE: UM ESTUDO SOBRE AS PESQUISAS DA ÁREA ENSINO DE CIÊNCIAS E MATEMÁTICA
}

\author{
France Fraiha-Martins* \\ Terezinha Valim Oliver Gonçalves**
}

RESUMO: Neste artigo, examinamos dissertações e teses sobre o uso da informática na educação matemática e científica nos anos iniciais de escolaridade, defendidas no âmbito da área ensino de Ciências e Matemática (46) no Brasil. Os referenciais teóricos que adotamos para analisar essas pesquisas são: Valente (1999), Almeida (2007), Haddad (2002), Franco (2003), dentre outros. Os resultados revelam que pesquisas, ao investirem na compreensão do ensino e/ou da aprendizagem utilizando informática como recurso, privilegiam estudo das potencialidades das tecnologias empregadas. Poucos trabalhos verticalizam de maneira epistêmica ou metodológica o papel docente em contextos em que a informática está inserida. Investir em pesquisas sobre essa temática é desejável, considerando as perspectivas da área de educação em Ciências e Matemática neste século.

Palavras-chave: Informática; Educação em Ciências e Matemática; Anos Iniciais do Ensino Fundamental.

\section{COMPUTERS IN MATHEMATICS AND SCIENCE EDUCATION IN THE FIRST YEARS OF SCHOOLING: A STUDY ON RESEARCH IN THE AREA OF MATHEMATICS AND SCIENCE TEACHING}

ABSTRACT: This article aims to review dissertations and theses on the use of computing in Maths and Science Education in the early years of schooling, within the defended area of Mathematics and Science Teaching (46). For this purpose, we are theoretically supported by Valente (1999), Almeida (2007), Haddad (2002), among others. This study shows that investing in research to understand the teaching / learning content using computers technology as a pedagogical tool privileges the study of the used technologies potential. Few studies deepen epistemic or methodogically the teacher's role in contexts in which computers are used. Investing in research on this topic it is desirable to discuss Science and Mathematics Education for this century.

Keywords: Informatics, Science and Mathematics education, early years of schooling.

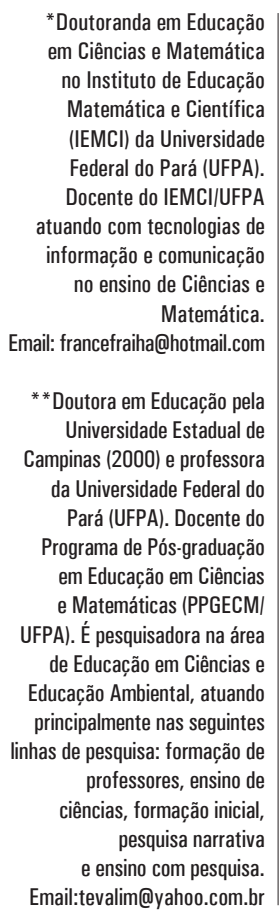




\section{INTRODUÇÃO}

Partindo do desejo investigativo de descrever e conhecer estudos acadêmicos realizados no âmbito de programas brasileiros de pós-graduação, sobre a utilização da informática na educação matemática e científica nos anos iniciais de escolaridade, buscamos desenvolver, nesta pesquisa, uma revisão de dissertações e teses, trazendo à tona aspectos e proposições destacados nesses estudos. Assim, pretende-se identificar, dentre outras nuances, as visões emergentes acerca do uso das tecnologias da informática em situações de ensino e de aprendizagem de Ciências e Matemática com crianças na fase inicial de aprendizagem escolar.

Embora reconheçamos que a temática informática na educação matemática e científica encontra-se em discussão, tanto nos programas brasileiros de pós-graduação da área Educação, quanto nos programas da Área Ensino de Ciências e Matemática (46) junto à CAPES ${ }^{1}$, fazemos a opção, neste artigo, de dar a conhecer o estado da pesquisa da área 46, no âmbito dessa temática.

Justificamos tal escolha por considerar relevante destacar, de modo sistemático, as características dessas produções, dando visibilidade a um panorama geral da área 46 acerca da inserção de ambientes computacionais nos processos educativos dos anos iniciais, a fim de suscitar reflexões sobre a temática, impulsionar pesquisas futuras, além de constituir um documento de registro dos caminhos percorridos por essas pesquisas nos primeiros dez anos de institucionalização da área 46 como área de pesquisa independente ${ }^{2}$.

Investir em pesquisas acerca da informática na educação matemática e científica no âmbito dos anos iniciais de escolaridade, a nosso ver, constitui-se ação necessária no campo científico-educacional, haja vista duas proposições que compreendemos justificadoras: em termos de avaliação educacional mundial, o Brasil ocupa o segundo pior ensino de Ciências e o pior ensino de Matemática do mundo ${ }^{3}$; a alfabetização digital ou tecnológica para o uso de recursos diferenciados no curso da aprendizagem torna-se imprescindível ao aluno desde o início de sua escolarização, na medida em que vivemos, neste século, relações sociais marcadamente mediadas pelas tecnologias de informação e comunicação.

Nesse sentido, investigar processos de ensinar e de aprender Ciências e Matemática - em ambientes que utilizam recursos informáticos no intuito de potencializar o desenvolvimento cognitivo do aluno - poderá contribuir para a melhoria da educação brasileira, em especial matemática e científica, ao tempo de possibilitar ao aluno o entendimento do papel das tecnologias educacionais como instrumentos de mediação de suas aprendizagens ao longo da vida (FRAIHA-MARTINS, 2009).

Outro aspecto a ser considerado é quanto ao uso desses recursos nos primeiros anos de escolaridade. Cada vez mais cedo, crianças estão em contato com as novas tecnologias em seu convívio social. Esse fator contribui para mudanças em suas maneiras de interagir e comunicar, na medida em que a maioria desses recursos traz como características constituidoras a multimídia e a hipertextualidade (MORAN, 2000). 
Nessa perspectiva, compreendemos que não há como ignorar a realidade tecnológica em que as crianças estão imersas, e que, portanto, urge a necessidade de recontextualização desses recursos no âmbito escolar, a fim de que sejam construídas habilidades e competências comunicativas e interativas em prol da aprendizagem significativa por parte dos alunos.

Daí a relevância do investimento nesse campo de pesquisa, buscando compreender os fenômenos educativos investigados com vistas à teorização e às novas experiências pedagógicas, passíveis de serem refutadas ou não, além da possibilidade de imprimir uma dupla educação digital: do professor e do aluno.

Sendo assim, este estudo, que pretende compreender as produções científicas da área 46 sobre essa temática, busca, além da interlocução visando à construção do conhecimento científico, somar esforços para o fortalecimento da própria área e dos profissionais que nela estão inseridos. Importa-nos ressaltar que o levantamento das pesquisas e as proposições aqui destacadas não podem ser considerados totalizantes, tampouco absolutamente atualizados, entretanto, servirá como ponto de partida para a discussão da temática que nos parece fundamental no atual momento brasileiro.

Para organizar e relatar este estudo, sistematizamos quatro tópicos: i) a navegação pela malha de conhecimento da área 46 (aspectos metodológicos); ii) caracterização geral das pesquisas; iii) significando as tecnologias da informática na educação em Ciências e Matemática; iv) apontamentos a considerar.

\section{A NAVEGAC̣ÃO PELA MALHA DE CONHECIMENTO DA ÁREA 46}

Para a realização deste estudo, em que pesquisamos dissertações e teses que abordam a temática informática na educação matemática e científica dos anos iniciais do Ensino Fundamental, produzidas no âmbito da área 46, optamos por um percurso investigativo de caráter qualitativo, buscando evidenciar o estado da arte ou estado do conhecimento (Ferreira, 2002).

Assumimos a pesquisa nessa perspectiva, por ser uma opção metodológica de investigação que busca a compreensão de certa temática por meio de sua sistematização e análise. Segundo Haddad (2002, p.9), estudos dessa natureza permitem, em um recorte temporal definido, sistematizar certo campo do conhecimento, identificar abordagens dominantes e emergentes, analisar criticamente as produções acadêmicas, bem como destacar lacunas ou campos inexplorados abertos a pesquisas futuras. Compreendendo essa proposta, definimos investigar os estudos acadêmicos a que nos propusemos, nos últimos dez anos, ou seja, no período de 2000 a 2010. Assim, imbuídos das proposições metodológicas, partimos para a navegação pela malha de conhecimento construída sobre o tema em questão por meio das redes digitais. Concordamos com Barreto (2001, p.5-6) ao dizer que a seleção de fontes de informação conta com os avanços da informática na medida em que é possível ter acesso aos bancos de dados digitais existentes na 
internet.

Nesses termos, optamos por fazer um levantamento inicial de todos os programas de pós-graduação vinculados a área 46, cuja informação foi adquirida no site da própria CAPES. Em seguida, tomamos a decisão de acessar individualmente os sites desses programas, por considerar o atendimento das instituições à exigência da CAPES. Em casos de insucesso, partimos para as bibliotecas digitais das universidades que sediam os programas. Essa dinâmica ocorreu ao longo dos 60 programas de pós-graduação ${ }^{4}$ cadastrados na área.

Após realizar essa navegação primeira, buscando abranger o máximo de pesquisas existentes - "garimpando" trabalhos que ainda não tinham sido encontrados - pesquisamos também no site da biblioteca digital de teses e dissertações (BDTD), bem como, no banco de teses da CAPES e no site Domínio Público.

Paralelamente à decisão do percurso de navegação pela malha virtual de conhecimento da área 46, definimos, a priori, alguns descritores que constassem no título das dissertações e teses, assegurando-nos certa afinidade dos resultados de busca com a temática em questão, conforme sugere Barreto (2001). Os descritores por nós definidos ao acessar os sites dos programas de pós-graduação foram: informática, tecnologias de informação e comunicação, software educativo, computador, internet, séries iniciais, anos iniciais de escolaridade, Ensino Fundamental.

De outro modo, ao acessar as bibliotecas virtuais das universidades, o BDTD, o banco da CAPES e o site Domínio Público, iniciamos a varredura pelos descritores associados aos anos iniciais, seguido dos descritores: ensino de Ciências, ensino de Matemática, educação em Ciências, educação matemática e educação em Ciências e Matemática. Esses foram os critérios definidos para ir ao encontro dos estudos, no formato digital, sobre o tema a ser investigado.

Além disso, como critério inicial de seleção das pesquisas a serem estudadas, elegemos aquelas que em seus resumos apontavam indícios de tratamento da temática que estávamos à procura. Nesses termos, ao lançarmo-nos à dinâmica navegante descrita acima, desenvolvemos a coleta inicial de 27 pesquisas, sendo 26 dissertações e 01 tese. Após a leitura dos resumos, iniciamos o processo de leitura sistemática das 27 pesquisas $^{5}$, privilegiando os seguintes aspectos: i) apresentação do estudo; ii) questões de pesquisa; iii) opções metodológicas; iv) sujeitos envolvidos na investigação e v) considerações finais acerca dos resultados alcançados.

Nesse processo, foram descartados 07 trabalhos (06 dissertações e 01 tese), pois foi constatado que: 02 pesquisas não utilizaram nenhum tipo de tecnologia da informática (nem das telecomunicações); 04 outras não tiveram o foco nos anos iniciais (lidavam com conteúdos curriculares do $6^{\circ}$ ao $9^{\circ}$ ano do Ensino Fundamental); e 01 pesquisa tratava da formação de professores do $2^{\circ}$ ciclo do Ensino Fundamental e do Ensino Médio.

Fazemos aqui um pequeno recorte para destacar que embora não tenha sido realizado o levantamento quantitativo de pesquisas no âmbito da informática na educação em Ciências e Matemática que envolve o $2^{\circ}$ ciclo do Ensino Fundamental e o Ensino Médio , por não ser esse o foco de nossa atenção investigativa neste 
momento, foi perceptível o elevado índice de pesquisas contemplando essas faixas de escolaridade em detrimento dos anos iniciais ou $1^{\circ}$ ciclo do Ensino Fundamental.

Sendo assim, para realizar o mapeamento proposto neste artigo, foram utilizados como material de análise um total de 20 dissertações. As descrições e análises realizadas acerca desse material foram desenvolvidas em duas perspectivas: i) caracterização geral das pesquisas; e ii) significando as tecnologias da informática na educação em Ciências e Matemática.

\section{CARACTERIZAC̣ÃO GERAL DAS PESQUISAS}

Tratamos, nesta seção, da descrição sistematizada das 20 dissertações em análise, enfatizando ano de publicação, foco central do estudo, tipo de pesquisa e instrumentos de coleta de dados privilegiados, objetivando identificar as abordagens dominantes e aquelas pouco utilizadas pelas pesquisas examinadas.

Iniciamos destacando que embora tenhamos definido o período de busca das produções entre os anos de 2000 e 2010, não foi localizada nenhuma pesquisa sobre a temática proposta nos anos de 2000 e 2001 no âmbito da área ensino de Ciências e Matemática. Desse modo, a área 46 apresenta indício de ter sua primeira pesquisa defendida sobre o tema informática na educação em Ciências no âmbito do Ensino Fundamental apenas no ano de 2002, por José Garcia da Rocha Filho, o qual abordou o ensino de Ciências - lixo, uma "usina" de aprendizagem - ao produzir um material didático em multimídia computacional que propunha um estudo interdisciplinar, partindo de um problema vivenciado no cotidiano do aluno.

Essa pesquisa, por sua vez, foi a única encontrada naquele ano, conforme apresentamos abaixo na figura 1 , em uma flecha do tempo que destaca a quantidade de produções, nessa temática, por ano:

Figura 1: quantidade de produções por ano

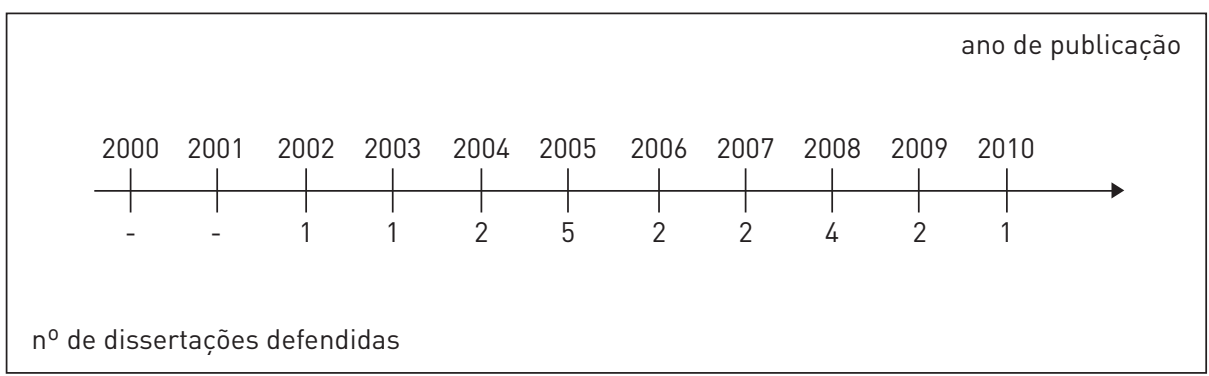

Das 20 dissertações defendidas, 16 pesquisas são oriundas de mestrados acadêmicos e 04 de mestrado profissional, o que revela a atenção maior dada à temática em questão pelos cursos de mestrado acadêmico. Outra observação que 
merece destaque é que 16 pesquisas do universo investigado foram produzidas nas regiões sul e sudeste, 03 na região nordeste, apenas 01 foi desenvolvida na região norte, e nenhuma na região centro-oeste. Tais dados parecem evidenciar uma realidade que, a nosso ver, é relevante destacar.

Referimo-nos à concentração elevada de programas de pós-graduação nas regiões mais desenvolvidas do Brasil em detrimento das demais regiões. Dos 60 programas de pós-graduação existentes na área ensino de Ciências e Matemática, 43 estão localizados nas regiões sul e sudeste, 08 na região nordeste, 06 na região centro-oeste e apenas 03 localizam-se na região norte. Isso revela a discrepância de recursos humanos qualificados entre as regiões, ou seja, de professores doutores para implantar e desenvolver programas de pós-graduação no âmbito da área 46.

Tal fato parece justificar o percentual de $80 \%$ das produções acadêmicas sobre a temática informática na educação em Ciências e Matemática dos anos iniciais originarem-se das regiões sul e sudeste. Isso se revela um fator preocupante se pensarmos em termos da democratização da alfabetização tecnológica, do acesso aos recursos digitais com equidade e da melhoria do ensino de Ciências e Matemática no país de modo igualitário, pois consideramos que os resultados de investigações no âmbito da pós-graduação podem contribuir significativamente para essa área de ensino, em especial nos contextos em que elas são desenvolvidas.

Visando romper com as assimetrias regionais nessa e em outras áreas do conhecimento e propiciar avanços locais mais rápidos, iniciativas intrarregionais têm surgido na região amazônica. Nesse sentido, doutores de instituições de Ensino Superior da Amazônia Legal organizaram-se para a criação da Rede Amazônica de Educação em Educação em Ciências e Matemática, por meio da qual estão formando novos doutores, dentre os docentes das Licenciaturas nessa área do conhecimento.

Outro aspecto a considerar é que dos 10 programas de pós-graduação vinculados às pesquisas sistematizadas neste estudo, apenas 02 deles não possuem linha de pesquisa específica que envolva as tecnologias de informação e comunicação nos processos de ensino e de aprendizagem de Ciências e/ou Matemática. Assim, programas que privilegiam linhas de pesquisa voltadas propriamente para essa temática apresentam indícios de atrair um número maior de pesquisadores interessados em investigar sobre esse tema.

Para identificar e descrever as pesquisas analisadas e seus respectivos programas de pós-graduação, apresentamos, a seguir, o Quadro 1, anunciando os autores, ano de publicação e descrevendo algumas de suas características constituidoras: 
Quadro 1: caracterização geral das pesquisas analisadas

\begin{tabular}{|c|c|c|c|}
\hline \multirow[t]{2}{*}{ INSTITUIC̣ÃO ${ }^{6}$} & \multirow[t]{2}{*}{ PESQUISADOR/ANO } & \multicolumn{2}{|l|}{ FOCO } \\
\hline & & ENSINO & APRENDIZAGEM \\
\hline PUC/RS & $\begin{array}{l}\text { Fuck (2010); Garcez (2009); } \\
\text { Rodrigues (2008) }\end{array}$ & $\begin{array}{l}\text { Matemática/ } \\
\text { Física }\end{array}$ & Ciências \\
\hline UFRGS & Damasio (2007); Machado (2005) & Física/Física & \\
\hline UFRPE & $\begin{array}{l}\text { Lima (2006); Rocha Filho (2002); } \\
\text { Henrique (2004) }\end{array}$ & $\begin{array}{l}\text { Ciências/ } \\
\text { Ciências }\end{array}$ & Física \\
\hline PUC/SP & $\begin{array}{l}\text { Santos (2003); Lima (2005); Accioli } \\
\text { (2005); Bagé (2008); Costa (2008); }\end{array}$ & $\begin{array}{l}\text { Matemática/ } \\
\text { Matemática }\end{array}$ & $\begin{array}{l}\text { Estatística/ } \\
\text { Matemática }\end{array}$ \\
\hline UFPA & Teixeira (2008) & Matemática & Matemática \\
\hline ULBRA & Soares (2005) & $\begin{array}{l}\text { Ciências e } \\
\text { Matemática }\end{array}$ & \\
\hline UEL & Chiarato (2005) & Matemática & \\
\hline UFSC & Abegg (2004); Geremias (2007) & $\begin{array}{l}\text { Ciências/ } \\
\text { Alfabetização } \\
\text { com letramento }\end{array}$ & \\
\hline CEFET/MG & Gomes (2006); Gontijo (2009) & $\begin{array}{l}\text { Escrita/ } \\
\text { Matemática }\end{array}$ & \\
\hline & & $\begin{array}{l}\text { Total: } 15 \\
\text { pesquisas }\end{array}$ & $\begin{array}{l}\text { Total: } 04 \\
\text { pesquisas }\end{array}$ \\
\hline & & \multicolumn{2}{|c|}{ Total: 01 ensino/aprendizagem } \\
\hline FOCO & $\begin{array}{l}\text { MODO INVESTIGATIVO } \\
\text { ESTRATÉGIA CENTRAL }\end{array}$ & \multicolumn{2}{|c|}{ TIPO DE PESQUISA ASSUMIDO } \\
\hline $\begin{array}{l}\text { FOCO } \\
\text { ENSINO }\end{array}$ & $\begin{array}{l}07 \text { pesquisas - experiência formativa; } \\
04 \text { pesquisas - intervenção no ensino; } \\
02 \text { pesquisas - observação da prática; } \\
02 \text { pesquisas - análise documental } \\
\text { e percepção dos sujeitos envolvidos } \\
\text { no contexto investigado. }\end{array}$ & \multicolumn{2}{|c|}{$\begin{array}{l}06 \text { qualitativa/estudo de caso; } \\
02 \text { qualitativa/metodologia } \\
\text { intervencionista 'design experiments'; } \\
03 \text { qualitativa; } \\
01 \text { qualitativa/exploratória e descritiva; } \\
01 \text { quantitativa e qualitativa do } \\
\text { tipo etnográfico; } \\
02 \text { qualitativa/ metodologia } \\
\text { investigação-ação escolar }\end{array}$} \\
\hline $\begin{array}{l}\text { FOCO } \\
\text { APRENDIZAGEM }\end{array}$ & $\begin{array}{l}04 \text { pesquisas por meio de } \\
\text { intervenção de ensino }\end{array}$ & \multicolumn{2}{|c|}{$\begin{array}{l}02 \text { qualitativa/estudo de caso } \\
01 \text { qualitativa/metodologia } \\
\text { intervencionista 'design experiments'; } \\
01 \text { quantitativa e qualitativa/plano } \\
\text { 'quase experimental' que se apoia } \\
\text { no plano clássico do experimento }\end{array}$} \\
\hline $\begin{array}{l}\text { FOCO } \\
\text { PROCESSO DE } \\
\text { ENSINO E } \\
\text { APRENDIZAGEM }\end{array}$ & $\begin{array}{l}01 \text { pesquisa por meio de } \\
\text { intervenção de ensino }\end{array}$ & \multicolumn{2}{|c|}{$\begin{array}{l}01 \text { qualitativa/estudo de caso/ } \\
\text { pesquisa-ação }\end{array}$} \\
\hline
\end{tabular}


É possível constatar, nessa revisão, que as pesquisas predominantemente trazem como foco central o ensino, num percentual de $75 \%$ do universo investigado, seguido de $20 \%$ situadas no foco aprendizagem e, ainda, há $5 \%$ desse conjunto que expressa abordar o processo de ensino e aprendizagem. Além disso, a Matemática configura-se como componente dominante nos objetos de estudo das pesquisas, seguido de Ciências e Física, encontrando-se menos privilegiados os componentes: a integração Ciências e Matemática, Estatística, Alfabetização com Letramento e Escrita.

Consideramos relevante mencionar que apenas 01 dissertação, aquela que expressa como foco central o processo de ensino e aprendizagem, investiu em pesquisa que insere a informática na educação matemática de crianças com necessidades educativas especiais, diferenciando-se das demais, as quais lidam com o ensino ou a aprendizagem de alunos ditos "normais".

Do ponto de vista metodológico das investigações, cabe destacar que todos os trabalhos são de natureza qualitativa, sendo que apenas 02 deles assumem complementar a análise com dados quantitativos. Das 15 pesquisas que trazem como foco central o ensino, 07 optaram por desenvolver experiências formativas ${ }^{7}$ com professores (sujeitos) envolvidos na pesquisa, 04 optaram por elaborar intervenções no ensino, propondo sequências didáticas, 02 realizaram observações de aulas ${ }^{8}$ dos professores inseridos nos contextos investigados e 02 outras pesquisas desenvolveram análise documental associada às percepções dos sujeitos envolvidos nos estudos, expressas por meio de entrevistas e questionários.

Já os 04 trabalhos que desenvolveram como foco central a aprendizagem e 01 que abordou o processo de ensino e aprendizagem fizeram opção por realizar intervenções de ensino, incidindo as análises sobre as ações e reações dos estudantes no contexto investigativo.

Frente a esse contexto, nos importa dizer que ao constatar, nesses trabalhos, que está sendo privilegiado o ensino por meio de experiência formativa e intervenção de ensino, é possível inferir que um aspecto que caracteriza a produção na área 46, no âmbito das dissertações produzidas sobre a temática em evidência, é buscar compreender e propor processos de formação de professores para o uso dos recursos da informática em práticas educativas, ou ainda, entender e gerar proposições em torno de uma determinada prática de uso.

Sob outro ponto de vista, em menor ênfase, surge o foco na aprendizagem por meio de intervenção de ensino, apontando indícios de que outro aspecto que caracteriza a área 46, nesse contexto, incide sobre as preocupações voltadas para produção de significados, sobre certo conteúdo curricular, favorecida pelas interações dos alunos com as tecnologias da informática.

Olhando sob outro enfoque metodológico, agora no âmbito das escolhas dos instrumentos de coleta de dados, aparece em maior número a observação participante por meio de notas de campo ou diários, totalizando 13 (65\%) das 20 pesquisas analisadas, que optaram por esse instrumento. Em seguida, surgem entrevistas semi-estruturadas e produções dos sujeitos envolvidos na pesquisa, processos utilizados em 11 dissertações (55\%). Em uma recorrência menor, aparecem questionários privilegiados 
em 05 pesquisas (25\%), pré-testes e pós-testes em 04 (20\%) delas, documentos formais em 03 (15\%) e áudio e vídeo também em $03(15 \%)$ pesquisas. Ressaltamos que foi utilizado nas pesquisas mais de um instrumento, portanto, as recorrências foram quantificadas.

Embora nos trabalhos tenha sido privilegiada a pesquisa qualitativa, associada às escolhas majoritárias pelas notas de campo, entrevistas e produçoes dos sujeitos como instrumentos de investigação, sabemos que quando se trata de definir conceitos e aspectos metodológicos, não existe consenso e alguns autores sugerem tratamentos bastante distintos em termos do que seja uma metodologia ou um método (VERMELHO e AREU, 2005). Assim, explicitamos as recorrências, considerando que entre elas existem as particularidades metodológicas definidas pelos autores, as quais não constituem, nesta produção textual, nosso foco de estudo.

Sendo assim, a seguir passamos a discutir sobre o tratamento dado à informática no âmbito da educação matemática e científica dos anos iniciais na área 46.

\section{SIGNIFICANDO AS TECNOLOGIAS DA INFORMÁTICA NA EDUCACְÃO EM CIÊNCIAS E MATEMÁTICA}

Ao sistematizar aspectos evidenciados sobre as tecnologias da informática na educação matemática e científica dos anos iniciais, voltamos nosso olhar para os recursos computacionais privilegiados nos trabalhos sob estudo e as visões emergentes das tecnologias tratadas pelos autores. Para tanto, lançamos mão da análise de conteúdo como metodologia de tratamento das informações contidas nas dissertações, buscando descrever, analisar e interpretar criticamente os significados das mensagens/enunciados (FRANCO, 2003)

Nesse sentido, iniciamos essas discussões descrevendo quantitativamente os recursos recorrentes, além dos singulares, no âmbito geral dos trabalhos revisados. Posteriormente, apresentamos análise qualitativa das visões das tecnologias educativas que emergem das pesquisas por meio de três categorias de análise definidas por nós: i) Foco no ensino; ii) Foco na aprendizagem e iii) Foco no processo de ensino e aprendizagem.

\subsection{Os recursos da informática privilegiados nos anos iniciais}

Os recursos que aparecem nos 20 estudos analisados, tal como estão descritos, são: software educativo (10); internet (07); recursos multimídia (03); ambiente virtual de aprendizagem (03); simulações computacionais (02); laboratório de informática (02); micromundo LOGO (1); e blog (1), ressaltando que em alguns trabalhos foram utilizados mais de um recurso. Essa descrição revela a predominância da opção pelo software educativo como um dos instrumentos tecnológicos utilizados nos processos investigativos de ensinar e aprender Ciências e Matemática nos primeiros anos de escolaridade, seguido da opção pela internet.

Se considerarmos a classificação de softwares utilizados na educação, proposta por Valente (1999), na qual consiste, dentre outros tipos, os sistemas multimídias, as simulações e as programações (linguagem LOGO), as pesquisas revisadas 
que fazem a opção por software educativo (10), tornam-se mais destacadas, ainda, pois seriam incorporados mais 06 trabalhos a essa quantidade de recorrência, já que em nenhuma dessas 06 pesquisas os respectivos autores consideram os instrumentos tecnológicos utilizados como software educativo, totalizando, portanto, 16 dissertações que fizeram essa opção.

Com efeito, se considerarmos, com Almeida (2007), que ambientes virtuais de aprendizagem são salas de aula virtuais disponíveis na internet que permitem desenvolver interações entre pessoas e objetos de conhecimento, e que blog é um sistema de publicação na internet destinado a divulgar informação por ordem cronológica, à semelhança de um diário, então, é possível agregar à recorrência internet (07) mais 04 repetições, perfazendo um total de 11 recorrências voltadas para as tecnologias da internet. Sendo assim, podemos considerar que os recursos privilegiados nas pesquisas em estudo estão contemplados em três amplos grupos: software educativo, internet e laboratório de informática.

Diante dessa perspectiva geral dos trabalhos, queremos destacar que se na seção anterior foi inferido que um dos aspectos que caracteriza a área 46, nos termos dessa temática, é a busca pela compreensão e por proposições de processos de formação de professores para o uso de recursos da informática em práticas educativas, frente à constatação acima também é possível inferir que esses processos de formação docente visam majoritariamente formar o professor para saber ensinar determinado componente curricular utilizando softwares educativos de variadas naturezas, seguido da formação que visa ao saber ensinar integrando os recursos da internet. E, em menor recorrência, estão as pesquisas que buscam compreender o modo de integração dos computadores às práticas educativas em laboratórios de informática. Sendo assim, passaremos às visões das tecnologias educativas que emergem das pesquisas por meio das categorias de análise a seguir.

\subsection{Foco no ensino}

As proposições desenvolvidas como resultados das pesquisas de Fuck (2010), Rodrigues (2008), Bagé (2008), Damasio (2007) e Santos (2003), sob o foco ensino utilizando software educativo, giram em torno do auxílio do ambiente computacional em processos de formação e desenvolvimento de conceitos por parte do professor, buscando, ao mesmo tempo, a formação docente para o ensino utilizando tal tecnologia. Na perspectiva da formação do professor, Santos (2003) destaca que na tentativa de adaptar atividades do livro didático para o ambiente computacional, o professor é levado a refletir sobre os conceitos matemáticos em estudo, pois permite rever esses conceitos para, então, construí-lo em ambiente computacional; daí a autora defender a ideia de que o professor constrói novos significados.

As análises de Bagé (2008) também consideram que o software educativo em processos formativos, possibilita ao professor rever conteúdos, dando a oportunidade de enxergá-los sob outros pontos de vista, além de expressar suas dúvidas no decorrer desses processos. Rodrigues (2008), por sua vez, vai mais além, apontando em sua pesquisa que os professores, ao expressarem suas dúvidas e 
reflexões, evidenciam obstáculos docentes de ordem conceitual, psico-cognitiva, metodológica, na compreensão, na explicação e na repercussão dos fenômenos físicos estudados ao passar da dimensão real para a virtual.

Em outra perspectiva, trabalhos como os de Machado (2005), Henrique (2004), Costa (2008), Gomes (2006) e Gontijo (2009) focam o ensino com uso de software educativo, partindo de sequências didáticas, no intuito de gerar proposições e reflexões acerca das repercussões produzidas em sala de aula quando escolhido esse recurso didático em determinadas propostas de ensino.

As análises de Costa (2008), Henrique (2004), Machado (2005) e Rocha (2002) caminham em direção à proposição de que a utilização de software educativo em situações de ensino poderá contribuir para a construção do conhecimento do aluno, na medida em que esse instrumento permite a revisitação ou aquisição de conteúdos novos por meio da exploração de imagens, sons, textos e vídeos; do levantamento de conjecturas; e das dinâmicas interativas entre os alunos, favorecidas pela utilização desse recurso. Acerca da interação entre os sujeitos envolvidos em ambientes computacionais, Gontijo (2009), em seus resultados, anuncia que situações de ensino que envolvem softwares educativos proporcionam uma dimensão interativa em sala de aula entre alunos, independentemente do professor e das divergências ou confluências entre suas concepções e aquelas implícitas nos próprios softwares.

Assim, nas perspectivas mencionadas sobre o uso de softwares educativos em processos de ensino, compreendemos que emerge a visão de que esses recursos possibilitam o avanço de conhecimentos que estão imbricados no contexto educativo, tanto para o professor quanto para o aluno, favorecendo a construção de novos significados.

Ainda no âmbito do foco ensino, a internet, segundo as pesquisas de Fuck (2010) e Damásio (2007), é considerada uma fonte de informação inesgotável para planejar e integrar as tecnologias da informática na docência. Fuck (2010) evidencia a existência de softwares livres disponíveis na internet capazes de favorecer a integração desses recursos no ensino de Matemática, assim como Damásio (2007) destaca a internet como um espaço que congrega inúmeros materiais pedagógicos virtuais de Física para as séries iniciais que podem ser aproveitados pelo professor em certas atividades didáticas.

Além disso, esses autores consideram favorável o uso da internet com criança por compreenderem que esse recurso desperta o interesse pelos conteúdos curriculares, pelo fato de esse instrumento tecnológico fazer parte da sociedade em que ela está imersa, aproximando o ambiente escolar da sua vida real.

Rodrigues (2008) e Chiarato (2005) manifestam, em suas análises, o entendimento de que a internet promove espaços virtuais interativos que instigam o professor - em processo de formação - ao questionamento, à reflexão e à construção coletiva do conhecimento, o que poderá repercutir na apropriação de novas concepções metodológicas de ensino, além da apropriação da ferramenta digital para o uso na prática docente. 
Compreendemos ser relevante destacar que essas pesquisas e as demais mencionadas neste texto manifestam a clareza de que a internet - além dos outros recursos já mencionados - por si só não garante as proposições qualitativamente positivas sobre ela, há a existência de outros elementos educativos que influenciam nos resultados. O que apresentamos como visões emergentes dessas tecnologias significam potencialidades que caracterizam esses recursos, expressas nas análises dos autores.

Geremias (2007), ao investigar como professoras dos primeiros dois anos iniciais do Ensino Fundamental estão utilizando e concebendo os computadores no processo de alfabetização de crianças em laboratórios de informática, destaca, em seus resultados, a compreensão de que a internet, assim como o computador, é um objeto social e mediador da relação entre o indivíduo e o mundo, não sendo, portanto, meramente instrumento técnico ou ferramenta. A autora compreende que as tecnologias da internet trazem consigo novos modos para as crianças pensarem, aprenderem e relacionarem-se com o conhecimento e, por conseguinte, novas maneiras de ensinar e aprender a ler e a escrever. Assim, Geremias (2007) aponta como um dos resultados da investigação que a internet e o computador utilizados no ensino dos anos iniciais trazem modificações no saber e no saber-fazer do professor (epistemológicas e metodológicas).

Além de Geremias (2007), Soares (2005) também investiu em pesquisa privilegiando o recurso laboratório de informática, que é destacado em apenas dois trabalhos dentre os revisados. Ambas as pesquisas trataram de questões que envolvem o modo como os professores integram às suas práticas os recursos computacionais existentes nos laboratórios de informática da rede pública de ensino. Soares (2005), na esteira das ideias de Geremias (2007), considera o laboratório de informática um espaço escolar que potencializa a possibilidade de acesso às informações e a comunicação da escola, do professor e do aluno com o mundo.

Enquanto isso, Soares (2005), ao desenvolver suas análises, entende que é preciso que a cultura escolar aproprie-se gradativamente dos recursos tecnológicos potencialmente educativos; Geremias (2007) enfatiza que a cultura tecnológica pode e deve ser desenvolvida na escola com as crianças, antes mesmo destas saberem ler e escrever. Em outra perspectiva, Soares (2005) expressa em seus resultados a proposição de que a deficiência no domínio de novas tecnologias pelos atuais docentes repercutirá de forma significativa na preparação de uma utilização eficiente do computador na educação em Ciências e Matemática dos anos iniciais. Compreendemos que a autora diz isso porque considera que sem conhecer as potencialidades educativas existentes nos recursos disponíveis nos laboratórios de informática, será pouco provável que o professor elabore situações de ensino com qualidade.

Como último destaque sob o foco ensino, não sendo o menos importante, surge, de modo singular nos trabalhos revisados, a pesquisa de Abegg (2004), na qual a autora não lida especificamente com o uso de tecnologias da informática, mas trata da necessidade de desenvolver processos de ensino nos anos iniciais que promovam discussões sobre a relação entre conhecimento científico e a produção 
de tecnologia, a fim de que os alunos, desde a infância, possam desenvolver a compreensão da tecnologia ${ }^{9}$ como meio para suprir necessidades humanas e favorecer a participação mais cidadã na sociedade. Abegg (2004) apoia-se nos parâmetros curriculares nacionais, os quais conclamam a um trabalho educativo voltado, além de outros aspectos, para o ensino de Ciências e suas tecnologias.

\subsection{Foco na Aprendizagem}

Indo ao encontro do outro grupo de trabalhos que considera como foco central a aprendizagem, surgem as pesquisas de Lima (2005), Accioli (2005), Lima (2006) e Garcez (2009). Lima (2005) e Accioli (2005) se ocupam da compreensão dos processos de aprendizagem dos alunos dos anos iniciais por meio de intervenções de ensino que utilizam como um dos recursos pedagógicos o software educativo. Nas duas pesquisas, os autores fazem a opção por escolher softwares de autoria.

Os estudos de Lima (2005) e Accioli (2005) são apoiados nas ideias de Valente (2003), o qual define que softwares de autoria utilizados na educação são aqueles considerados abertos à criação, à construção do aluno, que permitem a construção individual do conhecimento a partir de suas próprias ações (atividades de exploração, investigação e descoberta). Na perspectiva do software de autoria, o controle da aprendizagem recai sobre o aluno, dando-lhe oportunidade de visualizar e compreender o seu processo de aprendizagem sobre determinado conteúdo, uma vez que suas ações e interações com o software ficam explícitas.

Nesses termos, essas duas pesquisas compreendem software educativo como instrumento facilitador da aprendizagem, como afirma Lima (2005), por favorecer o desenvolvimento de habilidades necessárias à aprendizagem de determinados conteúdos. Nas palavras de Accioli (2005), isso ocorre pela necessidade de o aluno se expressar usando a linguagem formal no software em uso.

Nas análises de Accioli (2005), softwares dessa natureza têm um papel central nas situações de aprendizagem, pois requerem organização e exposição do pensamento do aluno. A autora, ao estabelecer relações entre o software e outras mídias também utilizadas em sua pesquisa, expressa a proposição de que não existem mídias melhores ou piores, uma complementa a outra, favorecendo o entendimento de conceitos. Nesse jogo de escolhas de diferentes mídias para atingir determinado objetivo de aprendizagem, Lima (2005) destaca o desenvolvimento da alfabetização tecnológica nos alunos.

Ainda miradas no grupo de trabalhos que traz como foco central a aprendiragem, destacamos que Garcez (2009) e Lima (2006) dedicam-se ao uso da internet em processos de aprendizagem, especificamente ao blog e ao ambiente virtual de aprendizagem (AVA). As autoras entendem que a virtualidade dessas tecnologias, associada à potencialidade de interação entre professor e alunos, e entre alunos, desperta interesse das crianças pelos conteúdos escolares.

Garcez (2009) destaca em sua pesquisa que dinâmicas educativas que envolvam os recursos da internet poderão auxiliar na integração e no retorno do aluno-paciente ao ambiente escolar, quando este permanece certo tempo afastado. Daí, a autora fazer menção ao ciberespaço, considerando-o, em sua análise, 
mediador no processo de aprendizagem. Já Lima (2006) afirma que as ferramentas da internet apresentam uma visão complexa da realidade por possibilitarem ações individuais e coletivas em um determinado grupo interativo, o que favorece o processo de aquisição de conhecimento.

\subsection{Foco no Processo de Ensino e Aprendizagem}

Como singularidade, neste estudo, surge a pesquisa de Teixeira (2008), que expressa como foco central o processo de ensino e aprendizagem. Constitui-se como singular por ser o único trabalho que trata de alunos com necessidades educativas especiais. Teixeira (2008), ao delinear práticas especialmente elaboradas para alunos com deficiência auditiva, busca fundamentar uma metodologia interdisciplinar, envolvendo o ensino da arte e da geometria com o apoio de software educativo.

A visão da autora acerca do software, apresentada por meio dos resultados da pesquisa, é a de que este se configura como um dos recursos pedagógicos desejáveis de serem utilizados, na medida em que facilita o processo ensino-aprendizagem para alunos surdos de maneira dinâmica, lúdica, colaborativa e interdisciplinar. O software utilizado na pesquisa tem cunho construcionista, proporcionando ao aluno a liberdade de expressão. Para Teixeira (2008), é fundamental privilegiar software educativo que valorize, sobretudo, os significados simbólicos e interativos tão necessários a essas crianças, a fim de motivá-las à aprendizagem.

Além disso, Teixeira (2008), partindo dos resultados alcançados na investigação, considera que há necessidade de investir em pesquisas que utilizem sistemas computacionais na educação de crianças com deficiência auditiva, a fim de alavancar a dinamização do uso dessas tecnologias na educação de pessoas com necessidades educativas especiais e de incluí-las, digital e socialmente, na sociedade produtiva.

Diante das inúmeras visões que emergem das tecnologias da informática no âmbito do tema aqui proposto e, sistematizadas nos três últimos subitens, fizemos a opção por manifestar, ao final dessas discussões, certa compreensão que desenvolvemos a respeito dos trabalhos acadêmicos aqui estudados.

Ao revisar os significados expressos, olhando para os contextos investigativos criados, pudemos perceber que, em geral, as pesquisas valorizam, dentre outros aspectos, a compreensão da influência desses recursos nos ambientes de aprendizagem que afetam professores e alunos, a influência das ferramentas computacionais em determinado contexto a partir das próprias características constituidoras desses recursos, daquelas que se apresentam evidentes.

Por exemplo, se determinado recurso foi concebido para favorecer a interatividade, é investigada essa potencialidade na relação professor/aluno, aluno/ aluno, ou ainda, em processo de formação do professor, apontando o desenvolvimento cognitivo e afetivo favorecido por esse instrumento. Se, por outro lado, o recurso computacional possibilita organização e exposição do pensamento por meio de registros textuais, esse fenômeno é investigado no âmbito das mesmas relações acima referidas. Ou seja, as proposições, em geral, são construídas em torno da potencialidade original do recurso, da potencialidade claramente observável. 
Não queremos dizer que isso não é desejável ou que não é relevante. Contudo, compreendemos que é preciso investir em pesquisas que tratem de características implícitas em certos recursos e que, por vezes, são adversas à determinada prática ou que não estejam potencialmente ativas ou claras.

Referimo-nos, por exemplo, a um software educativo de pouca interatividade e quase nenhum espaço para a criação e exposição do pensamento. Como integrá-lo em dinâmicas pedagógicas que valorizem a construção do conhecimento de quem o utiliza? Que elementos podem ser acrescentados a esse contexto de modo a 'ativar' ou 'criar' potencialidades nesse instrumento para o ensino ou para a aprendizagem de melhor qualidade? Entendemos que situações como essa são comuns no ambiente escolar, porque nem sempre o professor tem disponíveis os recursos almejados. Essa é a realidade das escolas públicas brasileiras.

Portanto, é essa perspectiva investigativa que, a nosso ver, as pesquisas pouco têm explorado. Situações como a exemplificada, que exigem competência do professor para que, dentro de uma situação real em sua prática docente, possa integrar instrumentos pedagógicos pertinentes (que estejam disponíveis) com vistas à compreensão dos conteúdos que se propõe a ensinar.

\section{APONTAMENTOS A CONSIDERAR}

Buscando desenvolver considerações acerca das interlocuções aqui travadas, iniciamos destacando que as pesquisas por nós examinadas, ao investirem na compreensão do ensino e/ou da aprendizagem de conteúdos utilizando as tecnologias da informática como ferramenta pedagógica, quando miram o foco nessas tecnologias dentro do contexto investigado, em geral privilegiam o desenvolvimento dos conteúdos ou o papel do recurso tecnológico como mediador do ensino ou da aprendizagem, enfatizando suas potencialidades.

No entanto, poucos trabalhos verticalizam de maneira epistêmica, ou metodológica, o papel mediador do professor em contextos pedagógicos em que a informática está inserida. Apoiados em Masetto (2006), entendemos por mediação pedagógica a atitude, o comportamento do professor que se apresenta com a disposição de ser uma ponte em movimento entre o aprendiz e sua aprendizagem, que ativamente colabora para que o aprendiz atinja seus objetivos.

Quando essas pesquisas manifestam as posturas desejáveis do professor frente à relação aluno/computador/conhecimento, restringem-se ao nível da generalização. Nesses termos, consideramos que pesquisadores vinculados à àrea 46 precisam, além de investir em estudos que envolvam a busca por potencialidades educativas em recursos da informática, nos quais elas aparentemente não existem e que estão disponíveis na realidade das escolas públicas, é preciso investir, também, no aprofundamento teórico-metodológico do papel docente frente a essa realidade, em especial às relações pedagógicas que se estabelecem entre aluno, máquina e conhecimento. 
Outro aspecto que consideramos relevante destacar, no âmbito das pesquisas acerca do processo de ensino por meio de experiências formativas, é que a minoria optou por acompanhar o professor em sua prática - posterior ou concomitantemente à experiência de formação - a fim de contribuir para a construção do seu conhecimento pedagógico especializado, o qual legitima-se na prática e constitui-se mais do que no conhecimento dos conteúdos curriculares (IMBERNÓN, 2006).

Portanto, concordamos com Almeida (2007) quando ele afirma que há necessidade de, cada vez mais, desenvolver processos formativos pautados em dinâmicas de retroalimentação, em que, partindo das reflexões sobre as ações educativas do grupo em formação, o professor reoriente suas práticas em contextos reais (com tecnologias) e, seguidamente, retorne ao grupo para compartilhar e apresentar feedbacks da experiência reorientada. Dinâmicas dessa natureza têm o intuito de provocar reflexões coletivas sobre o "feito diferente", construindo outros conhecimentos e atribuindo novos significados e sentidos às práticas docentes e às teorias compartilhadas (FRAIHA-MARTINS, 2009).

Quanto às descrições apresentadas, reiteramos a necessidade de fomentar pesquisas sobre a temática em questão por meio de programas de pós-graduação, principalmente nas regiões menos favorecidas, buscando igualdade de oportunidades de formação profissional e elevando a qualidade do ensino de Ciências e Matemática nessas regiões, já que consideramos que as investigações acadêmicas podem contribuir com os contextos em que elas são desenvolvidas.

Como último apontamento, ressaltamos as pesquisas singulares como as de Teixeira (2008), de Lima (2005) e de Abegg (2004), a fim de manifestar a relevância de produzir novos trabalhos que envolvam crianças com necessidades educativas especiais; que lidem com os conteúdos de estatística no âmbito dos anos iniciais; e que privilegiem discussões sobre as relações entre conhecimento científico e a produção de tecnologia. Isso é desejável para que esses trabalhos apresentados possam compartilhar e confrontar conhecimentos, de modo a ecoar e fortalecer esses objetos de pesquisa na educação matemática e científica, assim como outros trabalhos que venham apresentar-se de modo singular no âmbito da área 46.

\section{NOTAS}

${ }^{1}$ Coordenação de Aperfeiçoamento de Pessoal de Nível Superior

${ }^{2}$ A área 46 foi criada pela CAPES no ano de 2000. Até o ano anterior à sua criação, as pesquisas desenvolvidas sobre o ensino de Ciências e Matemática ficavam vinculadas à área Educação, o que vem ocorrendo até os dias atuais em alguns programas de pós-graduação na área Educação que mantêm linha de pesquisa em educação matemática e científica. A criação da área 46 tem contribuído para o avanço das pesquisas nessa área específica do conhecimento, assim como no desenvolvimento profissional de seus pesquisadores.

${ }^{3}$ De acordo com avaliação da Organização para a Cooperação e o Desenvolvimento Econômico OCDE, no ano de 2006. É possível ter acesso a essas informações por meio da lista completa do PISA em vários sites, dentre eles, www.epoca.com.br. 
${ }^{4}$ Informações contidas no site da CAPES atualizadas em 31/08/2010. Os 60 programas são caracterizados da seguinte forma: 11 programas de mestrado acadêmico, 01 programa de doutorado, 30 programas de mestrado profissional e 18 programas de mestrado acadêmico e doutorado.

${ }^{5}$ Das 27 pesquisas, não tivemos acesso aos arquivos digitais de apenas 03 dissertações. Esses trabalhos foram aproveitados por considerar que os respectivos resumos davam conta da caracterização geral do trabalho.

${ }^{6}$ Pontifícia Universidade Católica (PUC); Universidade Federal do Rio Grande do Sul (UFRGS); Universidade Federal Rural de Pernambuco (UFRPE); Universidade Federal do Pará (UFPA); Universidade Luterana do Brasil (ULBRA); Universidade Estadual de Londrina (UEL); Universidade Federal de Santa Catarina (UFSC); Centro Federal de Educação Tecnológica (CEFET).

${ }^{7}$ Atribuímos o termo experiência formativa à estratégia, utilizada pelo pesquisador, de realizar formação continuada junto aos sujeitos a fim de investigar o processo de formação docente e suas possíveis repercussões.

${ }^{8}$ Tais pesquisas assumem-se como estudos de caso. Fazem observações sem interferência na realidade investigada.

${ }^{9}$ A autora se apoia no conceito de tecnologia de Kenski (2003), em que se refere a um conjunto de conhecimentos e princípios científicos que se aplicam ao planejamento, à construção e à utilização de um equipamento em determinado tipo de atividade.

\section{REFERÊNCIAS}

ABEGG, I. Ensino-Investigativo de Ciências Naturais e suas Tecnologias nas Séries Iniciais do Ensino Fundamental. 2004. 120f. Dissertação (Mestrado em Educação Científica e Tecnológica) - Universidade Federal de Santa Catarina, Florianópolis (SC), 2004.

ACCIOLI, R. M. Robótica e as Transformações Geométricas: um estudo exploratório com alunos do ensino fundamental. 2005. 248f. Dissertação (Mestrado em Educação Matemática) - Pontifícia Universidade Católica/SP, São Paulo (SP), 2005.

ALMEIDA, M.E.B. A construção compartilhada de significados em projetos de educação a distância. In: VALENTE, A; ALMEIDA, M. E. B. (Orgs). Formação de educadores a distância e integração de mídias. São Paulo: Avercamp, 2007.

BAGÉ, I. B. Proposta para a Prática do Professor do Ensino Fundamental I de Noções Básicas de Geometria com o uso de Tecnologias. 2008. 199f. Dissertação (Mestrado Profissional em Ensino da Matemática) - Pontifícia Universidade Católica/SP, São Paulo (SP), 2008.

BARRETO, E. S. S; PINTO, R.P. Avaliação da educaşão básica (1990-1998). Brasília, DF: MEC/Inep/ Comped, 2001. (Estado do Conhecimento no 4)

CHIARATO, M. A. L. M. Aprendendo Matemática a Distancia: a circulação do conhecimento em um Curso de Formação das séries de Professores iniciais. 2005. 85f. Dissertação (Mestrado em Ensino de Ciências e Educação Matemática) - Universidade Estadual de Londrina (UEL), Londrina (PR), 2005.

COSTA, A. O. Proposta de uma Oficina para a Prática Docente no Ensino Fundamental: utilizando o Cabri na investigação de quadriláteros. 2008. 173f. Dissertação (Mestrado Profissional em Ensino da Matemática) - PUC/SP, São Paulo (SP), 2008.

DAMASIO, F. Programa para Qualificação de Professores para Ensino de Física em Séries Iniciais do Ensino Fundamental. 2008. 247f. Dissertação (Mestrado Profissional em Ensino de Física) - Universidade Federal do Rio Grande do Sul, Porto Alegre (RS), 2007.

FERREIRA, N. S. A. As Pesquisas Denominadas "Estados da Arte". Educaşão \& Sociedade, Campinas, ano XXIII, no 79 , 257-272, agosto/2002. 
FRAIHA-MARTINS, F. Nexos e Reflexos de uma Experiência Formativa Mediatizada por Ambiente Virtual de Aprendizagem: formação de professores de ciências e matemática na Amazônia. 2009. 213 f. Dissertação (Mestrado em Educação em Ciências e Matemática) - Instituto de Educação Matemática e Científica, Universidade Federal do Pará, Belém (PA), 2009.

FUCK, R. S. A Integração das Tecnologias Informáticas no Contexto da Prática Docente: um estudo de caso com professores de matemática. 2010. 137f. Dissertação (Mestrado em Educação em Ciências e Matemática) - Faculdade de Física, Pontifícia Universidade Católica do Rio Grande do Sul, Porto Alegre (RS), 2010.

GARCEZ, C. R. Utilizando Blog e suas Ferramentas para Auxiliar e Integrar o Aluno-Paciente à Escola: um estudo de caso na área de Ciências. 106f. Dissertação (Mestrado em Educação em Ciências e Matemática) - Faculdade de Física, Pontifícia Universidade Católica do Rio Grande do Sul, Porto Alegre (RS), 2009.

GEREMIAS, B. M. Entre o Lápis e o Mouse: práticas docentes e tecnologias da comunicação digital. 2007. 127f. Dissertação (Mestrado em Educação Científica e Tecnológica) - Universidade Federal de Santa Catarina, Florianópolis (SC), 2007.

GOMES, M. A. F. Narrativa em Ambiente Informatizado: análise de atividade proposta no CD-ROM (Compact Disc Reading Only Memory) "Recontando Histórias". 2006. 168f. Dissertação (Mestrado em Educação Tecnológica) - Centro Federal de Educação Tecnológica de Minas Gerais, Belo Horizonte (MG), 2006.

GONTIJO, F. L. Software Educativo na Prática de Ensino: confluências e divergências conceituais e implicações didáticas. 2009. 160f. Dissertação (Mestrado em Educação Tecnológica) - Centro Federal de Educação Tecnológica de Minas Gerais, Belo Horizonte (MG), 2009.

HADDAD, S. Jwventude e escolarização: uma análise da produção de conhecimentos. Brasília, DF: MEC/ Inep/Comped, 2002. (Estado do Conhecimento no 8)

HENRIQUE, V. V. A. Softwwares Educacionais no Ensino de Ciências: uma avaliação sob o enfoque da teoria da flexibilidade cognitiva (TFC). 2004. 116f. Dissertação (Mestrado em Ensino de Ciências) Universidade Federal Rural de Pernambuco, Recife (PE), 2004.

IMBERNÓN, F. Formaşão docente e profissional: formar-se para a mudança e a incerteza. 6. ed. São Paulo: Cortez, 2006. (Coleção Questões da Nossa Época)

LIMA, J. R. B. O Ambiente Virtual de Estudo e a Formação dos Conceitos Científicos nas Séries Iniciais do Ensino Fundamental. 2006. 127f. Dissertação (Mestrado em Ensino de Ciências) - Universidade Federal Rural de Pernambuco, Recife (PE), 2006.

LIMA, R. C. R. Introduzindo o Conceito de Média Aritmética na 4ª Série do Ensino Fundamental Usando o Ambiente Computacional. 2005. 230f. Dissertação (Mestrado em Educação Matemática) - Pontifícia Universidade Católica de São Paulo, São Paulo (SP), 2005.

MACHADO, M. A. Desenvolvimento e Implementação de Unidades Didáticas na Formação de Professores das Séries Iniciais. 2005. 181f. Dissertação (Mestrado Profissional em Ensino de Física) - Universidade Federal do Rio Grande do Sul, Porto Alegre (RS), 2005.

MASETTO, M. T. Mediação pedagógica e o uso da tecnologia. In: MORAN, J. M; MASETTO, M.T; BEHRENS, M. A. Novas tecnologias e mediação pedagógica. 12. ed. Campinas, SP: Papirus, 2006. (Coleção Papirus Educação)

MORAN, J.M. Ensino e aprendizagem inovadores com tecnologias audiovisuais e telemáticas. In: MORAN, J.M; MASETTO, M. T; BEHRENS, M. A. Novas tecnologias e mediação pedagógica. Campinas, SP: Papirus, 2000 (Coleção Papirus Educação)

ROCHA FILHO, J. G. A Construção de uma Multimídia como Tema Gerador: lixo, uma "usina" de aprendizagem. 2002. 169f. Dissertação (Mestrado em Ensino de Ciências) - Universidade Federal Rural de Pernambuco, Recife (PE), 2002.

RODRIGUES, C. R. Ensino de Física nas Séries Iniciais: um estudo de caso sobre formação docente com ênfase na experimentação e na informática educativa. 2008. 130f. Dissertação (Mestrado em Educação em Ciências e Matemática) - Faculdade de Física, Pontifícia Universidade Católica do Rio Grande do Sul, Porto Alegre (RS), 2008. 
SANTOS, S. S. O Desenvolvimento de Conceitos Elementares do Bloco de Tratamento da Informação com o Auxílio do Ambiente Computacional: um estudo de caso com uma professora do $1^{\circ}$ e $2^{\circ}$ ciclos do Ensino Fundamental. 2003. 251f. Dissertação (Mestrado em Educação Matemática) - Pontifícia Universidade Católica de São Paulo, São Paulo (SP), 2003.

SOARES, K. F. Computadores na Educação x Formação de Professores. 2005. 197f. Dissertação (Mestrado em Ensino de Ciências e Matemática) - Universidade Luterana do Brasil, Canoas (RS), 2005.

TEIXEIRA, B. F. C. Geometria Perceptiva, Arte e Informática na Educação de Surdos nas Séries Iniciais. 2008. $100 \mathrm{f}$. Dissertação (Mestrado em Educação em Ciências e Matemática) - IEMCI/UFPA, Belém (PA), 2008.

VERMELHO, S.C; AREU, G.I.P. Estado da arte da área de educação \& comunicação em periódicos brasileiros. Educ. Soc., Campinas, vol. 26, n. 93, p. 1413-1434, Set./Dez. 2005 Disponível em: $<$ http://www.cedes.unicamp.br>. Acesso em 30 set. 2010.

VALENTE, J. A. Análise dos diferentes tipos de softwares usados na educação. In: VALENTE, J. A. (Org.). O computador na sociedade do conhecimento. Brasília: Ministério da Educação, 1999 (Coleção Informática para a mudança na educação).

Data do Recebimento: 02/03/2011

Data de Aprovação: 24/12/2011

Data da Versão Final: 30/01/2012 